\title{
VISUALISASI KONTRAS SPEKEL MENGGUNAKAN PROGRAM SCIKIT IMAGE DAN PULSA DETAK JANTUNG BERBASIS ARDUINO UNO PADA TIKUS PUTIH YANG DIINDUKSIKAN ALOKSAN
}

\author{
Zulkarnain, Nur Melati* \\ Program Studi S1 Fisika FMIPA, Universitas Riau \\ *E-mail korespondensi: nurmelati989@gmail.com
}

\begin{abstract}
Speckle contrast visualization and heart rate pulses on rats induced with alloxan were successfully carried out. This research aims to visualize speckle contrast measurements using the Scikitimage program and analyze the relationship between speckle contraston rats to blood sugar levels and also to determine the effect of alloxan induced on heart rate frequency in rats. This study obtained speckle pattern image data from rats induced by alloxan with variations in concentrations of $35 \%, 55 \%$ and without alloxan for 12 days of treatment. The sample used were 3 to 5 months old. The method conducted in speckle contrast visualization was using blob detection with Laplacian of Gaussian algorithm to obtain speckle contrast values while the visualization of heart rate pulse based on Arduino Uno was done using the Integrated Development Environment (IDE) program. The results obtained from image processing using the Scikitimage program show that the contrast value could achieved decreasing with increasing blood sugar levels and the results obtained for detection of heart rate was the greater the blood sugar level the greater the heart rate (beat per minute) measured.
\end{abstract}

Keywords: Blob detection, Heartbeat, Alloxan, Rat

\begin{abstract}
ABSTRAK
Visualisasi kontras spekel dan pulsa detak jantung pada tikus putih yang diinduksikan dengan aloksan telah berhasil dilakukan. Penelitian ini bertujuan untuk memvisualkan kontras spekel dengan menggunakan program Scikit image dan menganalisis hubungan kontras spekel pada tikus putih terhadap kadar gula darah serta mengetahui pengaruh pemberian aloksan terhadap frekuensi detak jantung pada tikus putih. Penelitian ini memperoleh data citra pola spekel dari tikus putih yang diinduksikan aloksan dengan variasi konsentrasi 35\%, 55\% serta tanpa aloksan selama 12 hari perlakuan. Sampel yang digunakan berumur 3 hingga 5 bulan. Metode yang digunakan pada visualisasi kontras spekel adalah metode blob detection dengan menggunakan algoritma Laplacian of Gaussian untuk mendapatkan nilai kontras spekel sedangkan pada visualisasi pulsa detak jantung berbasis Arduino Uno dilakukan dengan menggunakan program Integrated Development Environment (IDE). Hasil yang diperoleh dari pengolahan citra menggunakan program Scikit image menunjukan bahwa nilai kontras semakin kecil seiring kenaikan kadar gula darah dan hasil yang diperoleh dari deteksi detak jantung adalah semakin besar kadar gula darah semakin besar detak jantung (beat per minute) yang terukur.
\end{abstract}

Kata kunci: Deteksi blob, Detak jantung, Aloksan, Tikus putih

\section{PENDAHULUAN}

Perkembangan dunia medis saat ini sangat mendukung terhadap peningkatan kualitas kesehatan dan daya hidup manusia. Semakin banyak penemuan-penemuan baru mengenai cara pengobatan maupun pencegahan berbagai penyakit ditemukan. Salah satu penyakit yang terkenal adalah diabetes mellitus. Diabetes mellitus adalah sindroma gangguan metabolisme yang timbul pada seseorang karena adanya peningkatan kadar glukosa darah diatas nilai normal akibat kekurangan insulin baik secara absolut maupun relatif [1].

Penelitian terkait pengukuran kadar gula darah secara non invasive dan non destructive dapat menggunakan metode pencitraan laser 
spekel[2].Pencitraan laser spekel menampilkan pola spekel yang berupa bintik-bintik atau bulir terang gelap yang terbentuk dari interferensi cahaya secara acak akibat penyinaran laser koheren yang mengenai permukaan objek seperti pada kulit manusia[3].Setiap pola spekel yang terbentuk memberikan informasi mengenai objek atau organisme hidup yang disinarinya, misalnya informasi tentang pergerakan sel darah merah [4].Pencitraan laser spekel baru dikembangkan pada berbagai bidang terutama dibidang medis untuk melakukan pendeteksian berbagai penyakit termasuk penyakit pada gula darah karena mampu mendeteksi sinyal optik dari jaringan hidup[5]. Penggunaan metode pencitraan laser spekel pada jaringan hidup banyak dilakukan saat ini sepertimenentukan pemetaan dinamika aliran darah pada serebrum tikus putih dengan menggunakan pencitraan laser spekel berdasarkan analisis kontras spekel[6] dan investigasi penggunaan metode Laser Speckle Imaging (LSI) untuk pengukuran kadar gula darah [7].

Metode blob detection atau deteksi titik merupakan suatu metode untuk mendeteksikumpulan titik-titik atau blob pada citra yang berbeda sifatnya seperti kecerahan atau warna[8]. Metode deteksi blob ini merupakan salah satu metode yang ada pada toolkit Scikit image dimana metode ini menggunakan algoritma Laplacian of Gaussian untuk memvisualkan citra dengan penghitungan nilai kontras. Penentuan kadar gula darah berdasarkan nilai kontras dapat menggunakan metode blob detection.

Penelitian ini diharapkan dapat digunakan dalam bentuk mobile atau portable yang dapat dibawa kemana saja sehingga memudahkan pengguna dalam mendeteksi kadar gula darah dan melihat pola spekel serta memberikan informasi yang lebih rinci mengenai konsentrasi kadar gula darah.Selain hubungan kontras spekel terhadap kadar gula darah, detak jantung tikus putih juga perlu dianalisis. Individu dengan detak jantung yang lebih cepat memiliki 59\% peningkatan resiko diabetes dibandingkan dengan individu yang denyut jantungnya lebih lambat[9], oleh karena itu dalam penelitian ini detak jantung tikus putih juga dianalisis sehingga dapat mengetahui hubungan terhadap pengaruh konsentrasi aloksan yang diinduksikan.

\section{METODE PENELITIAN}

Penelitian ini dilakukan dengan metode komputasi yang menggunakan data primer dari metode Laser Speckle Imagingdengan menggunakan tikus putih sebanyak 15 ekor sebagai sampel penelitian.Proses pengambilan data primer terhadap tikus putih dilakukan pada hari ke 8 hingga hari ke 12 setelah penginduksian aloksan dengan konsentrasi aloksan 35\%, 55\% serta tanpa induksi aloksan. Data citra pola spekel tersebut direkam oleh kamera CMOS monokrom.

Data primer tersebut diolah dengan program yang dirancang dengan menggunakan Scikit image sedangkan detak jantung tikus putih divisualkan menggunakan Arduino Uno. Data citra pola spekel dan detak jantung tikus putih tersebut dianalisa dengan beberapa tahapan sebagai berikut :

1) Merancang dan membuat program pengolah citra pola spekel dengan menggunakan Scikit image.Pembuatan program diawali dengan pembuatan bagan alir program agar dalam pengolahan data dapat dilakukan secara sistematis. Bagan alir program dapat dilihat pada gambar 1 . Program pengolah citra dirancang dengan menggunakan metode blob detection dimana metode ini mengaplikasikan operator Laplacian of Gaussian sebagai pendekatan untuk memperoleh standar deviasi. Laplacian of Gaussian merupakan kombinasi dari filter Gaussian dan deteksi tepi Laplacian. Adapun persamaan Laplacian memiliki bentuk:

$L(x, y)=\nabla^{2} f(x, y)=\frac{\partial^{2} f}{\partial x^{2}}+\frac{\partial^{2} f}{\partial y^{2}}$

Persamaan fungsi Gaussian dua dimensi sebagai berikut : 
$G(x, y)=\frac{1}{\sqrt{2 \pi u^{2}}} e^{-\frac{x^{2}+y^{2}}{2 a^{2}}}$

Sehingga untuk persamaan akhir yang ingin didapatkan yaitu Laplacian of Gaussian dapat diperoleh formulasi akhir sebagai berikut :

$L \quad(x, y)=-\frac{1}{\pi \sigma^{4}}\left[1-\frac{x^{2}+y^{2}}{2 \sigma^{2}}\right] e^{-\frac{\alpha^{2}+y^{2}}{2 \sigma^{4}}}$

dimana $\mathrm{x}$ adalah jarak asal sumbu horizontal, y adalah jarak dari sumbu vertikal, dan $\sigma$ adalah standar deviasi dari distribusi Gaussian[10].

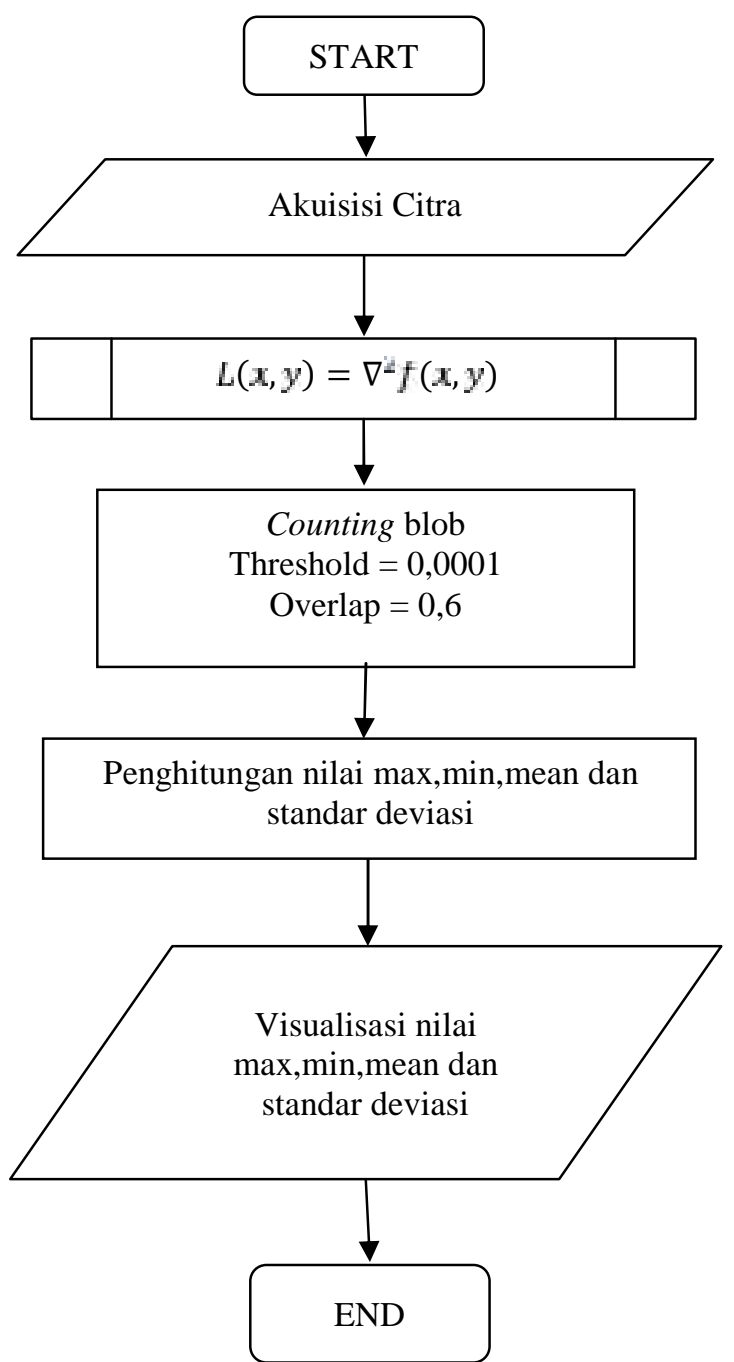

Gambar 1.Bagan alir visualisasi kontras spekel

2) Data citra pola spekel diperoleh dari tikus putih yang diinduksikan kadar aloksan sebanyak 35\%, 55\% serta tanpa aloksan dan direkam oleh kamera CMOS monokrom dimana citra yang direkam akan ditampilkan oleh laptop dengan software free webcam recorder lalu divisualisasikan dengan program yang dirancang sehingga mendapatkan nilai max,mean,min dan standar deviasi. Nilai yang didapatkan akan digunakan untuk menghitung nilai kontras dari citra pola spekel tersebut serta menampilkan plot atau histogram. Nilai kontras dapat diperoleh dengan menggunakan persamaan 3 yaitu :

$K=\frac{\sigma}{l}=\frac{\sqrt{\langle l \mid>-<l\rangle^{2}}}{<l>}$

Kontras spekel didefinisikan pada persamaan 3, dimana $\sigma$ merupakan standar deviasi dari intensitas I dan $<$ I > merupakan intensitas rata-rata[4].

3) Pulsa detak jantung tikus putih direkam menggunakan pulse sensor yang terintegrasi dengan Arduino Uno. Sensor ini dapat mendeteksi detak jantung pada telinga tikus putih dengan cara menggabungkan data detak jantung dari sensor dengan program di mikrokontroler lalu didapatkan nilai bpm yaitu detak jantung per satuan waktu yang biasanya dinyatakan dalam beats per minute (bpm).

\section{HASIL DAN PEMBAHASAN}

\section{Visualisasi Kontras Spekel}

Hasil dari pengolahan data disajikan dalam bentuk histogram dan plot scatter untuk menampilkan visualisasi kontras dan detak jantung pada tikus putih serta hubungan nilai kontras dengan gula darah. Hasil dari visualisasi kontras spekel dengan program scikit image berupa histogram dapat dilihat pada gambar 2. Histogram yang diperoleh merupakan kurva pola distribusi Gaussian dengan menggunakan persamaan Laplacian of Gaussian.Kurva pada histogram citra pola spekel membentuk distribusi yang simetris. 
Diabric Rats A nalyzine Too's
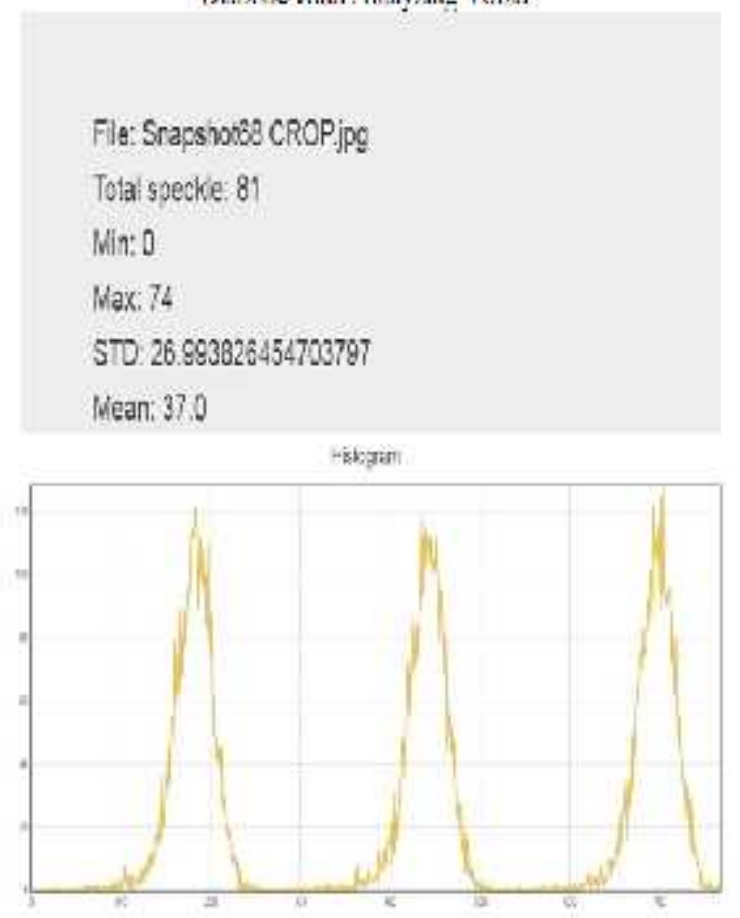

Gambar 2. Histogram dan pengukuran kontras dari citra pola spekel pada konsentrasi $35 \%$ pada hari ke 8 .

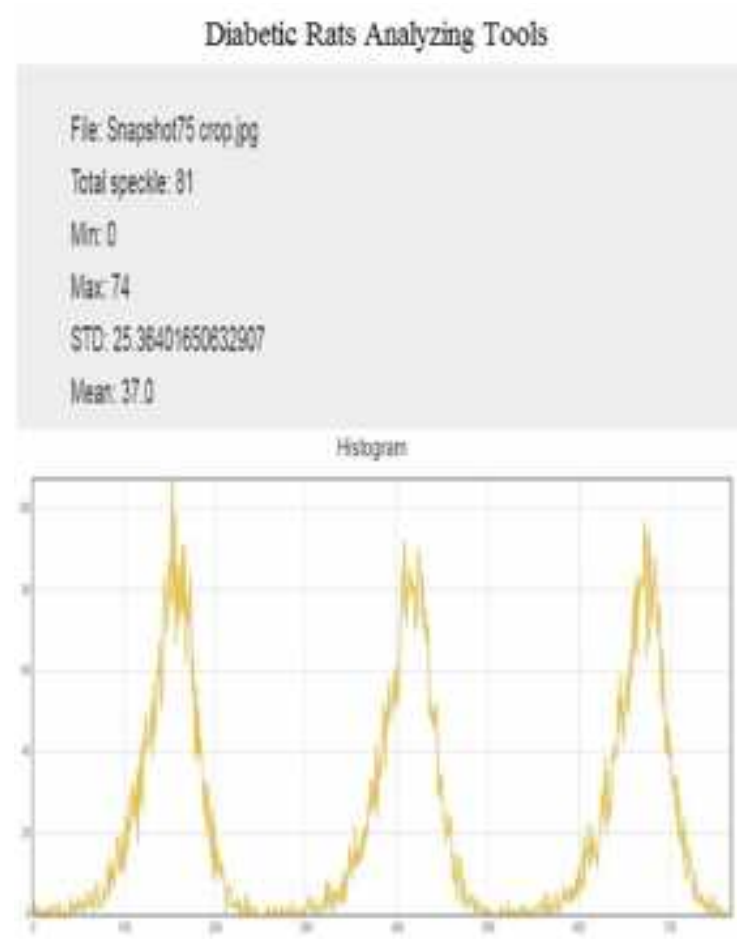

Gambar 3. Histogram dan pengukuran kontras dari citra pola spekel pada konsentrasi $55 \%$ pada hari ke 8 .
Diabetic Rats Analyzing Tools

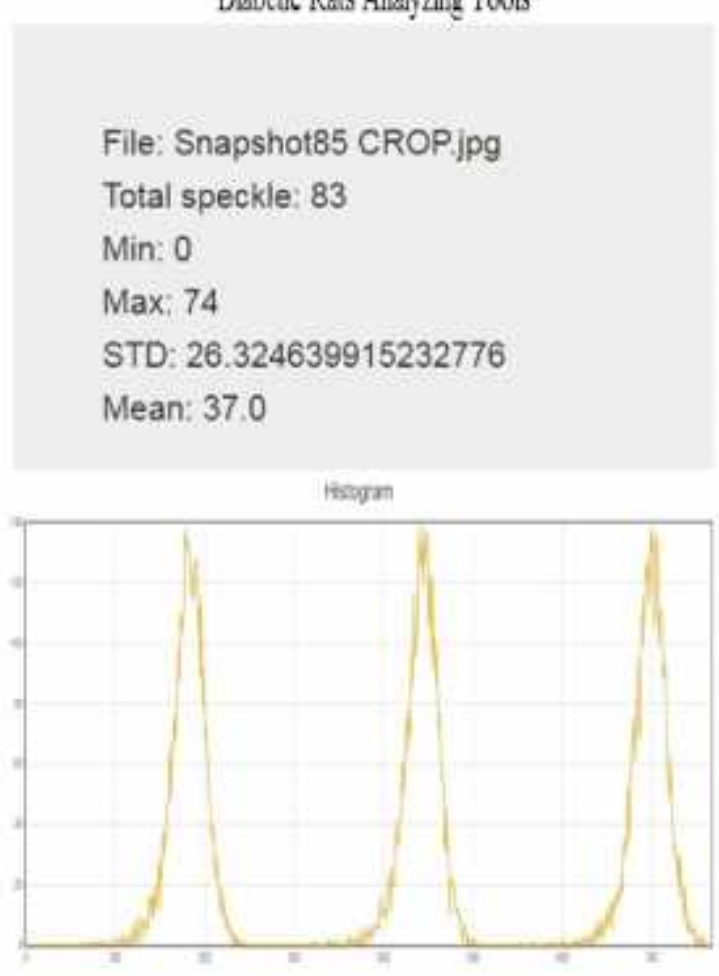

Gambar 4. Histogram dan pengukuran kontras dari citra pola spekel pada konsentrasi $0 \%$ (tanpa aloksan) pada hari ke 8 .

Gambar 2 merupakan gambar histogram citra dari kelompok konsentrasi aloksan 35\% pada hari ke-8. Grafik menunjukan bahwa puncak histogram lebih tinggi disebelah kanan, oleh karena itu citra ini dapat dikatakan pola spekelnya lebih cenderung terang. Gambar 3 merupakan gambar histogram citra dari kelompok konsentrasi aloksan 55\% pada hari ke-8, puncak histogram lebih tinggi disebelah kiri, oleh karena itu citra ini memiliki pola spekel yang cenderung lebih gelap.Gambar 4 merupakan histogram citra dari kelompok konsentrasi aloksan 0\% atau tanpa aloksan pada hari ke-8.Histogram tersebut menunjukkan bahwa histogramnya tersebar merata karena mengisi daerah keabuan secara penuh dengan distribusi yang merata pada setiap nilai intensitas piksel dan meningkatkan persebaran nilai grayscale sehingga citra terkesan lebih terang dan detailnya lebih terlihat.Nilai intensitas (mean), min, max, jumlah spekel dan standar deviasi diperoleh dari program pengolah citra Diabetic Rats Analyzing Tools. Nilai intensitas lebih besar 
dari nilai standar deviasi. Nilai kontras yang diperoleh pada konsentrasi $35 \%$ sebesar 0,72956 a.u dengan konsentrasi gula darah 92 $\mathrm{mg} / \mathrm{dL}$, pada konsentrasi $55 \%$ nilai kontras sebesar 0,68551 a.u dengan kadar gula darah $551 \mathrm{mg} / \mathrm{dL}$ sedangkan pada saat tanpa induksi aloksan nilai kontras yang diperoleh sebesar 0,71147 a.u dengan kadar gula darah 119 $\mathrm{mg} / \mathrm{dL}$.

Berdasarkan pengamatan yang dilakukan terhadap histogram yang diperoleh, dapat diamati bahwa nilai standar deviasi semakin besar pada setiap kenaikan nilai kontras. Naiknya nilai kontras tersebut berimbas pada bertambahnya nilai kontras yang dihasilkan oleh masing-masing berkas sinar yang mengenai permukaan sampel.Puncak yang berada disebelah kanan dikarenakan citra pola spekel nya cenderung lebih terang dibandingkan citra pola spekel yang puncaknya berada disebelah kiri.Penyebab terjadinya perbedaan pola berasal dari pemantulan dan penyebaran sinar yang semakin tak teratur sehingga mengurangi jumlah sinar yang terpantul kembali ke kamera.

Kontras dapat diartikan selisih perbedaan terang gelap yang muncul pada fenomena citra pola spekel ini, dimana kontras tinggi menyatakan semakin fokusnya pantulan cahaya kembali setelah melewati suatu permukaan. Pengertian tersebut menunjukan bahwa semakin homogen suatu permukaan akan mempengaruhi tingkat kontras suatu pancaran sinar yang mengenai permukaan[11]. Nilai kontras dihasilkan dari peristiwa interferensi yang terjadi pada sinar laser yang mengenai permukaan sampel.

\section{Hubungan Kontras Spekel Terhadap Kadar Gula Darah}

Setiap citra dihitung menggunakan program pengolah citra yang dibuat dengan software Scikit image.Citra pola spekel yang didapatkan adalah hasil dari citra yang direkam pada bagian kepala tikus putih yang diambil sebanyak 10 kali lalu dirata-ratakan nilai kontrasnya.

Tabel 1.Nilai rata-rata kontras spekeldan kadar gula darah pada konsentrasi 35\%

\begin{tabular}{ccc}
\hline Hari & $\begin{array}{c}\text { Gula } \\
\text { Darah } \\
(\mathrm{mg} / \mathrm{dL})\end{array}$ & $\begin{array}{c}\text { Kontras } \\
\text { rata-rata } \\
(\text { a.u })\end{array}$ \\
\hline 8 & 92 & 0,72494 \\
9 & 157 & 0,70633 \\
10 & 116 & 0,70622 \\
11 & 101 & 0,71234 \\
12 & 109 & 0,70842 \\
\hline
\end{tabular}

Nilai rata-rata kontras tertinggi adalah pada hari ke 8 yaitu sebesar 0,72494 a.u dan kontras rata-rata terendah pada hari ke 10 yaitu sebesar 0,70622 a.u. Nilai kontras semakin menurun seiring meningkatnya kadar gula darah akibat pengaruh aloksan.

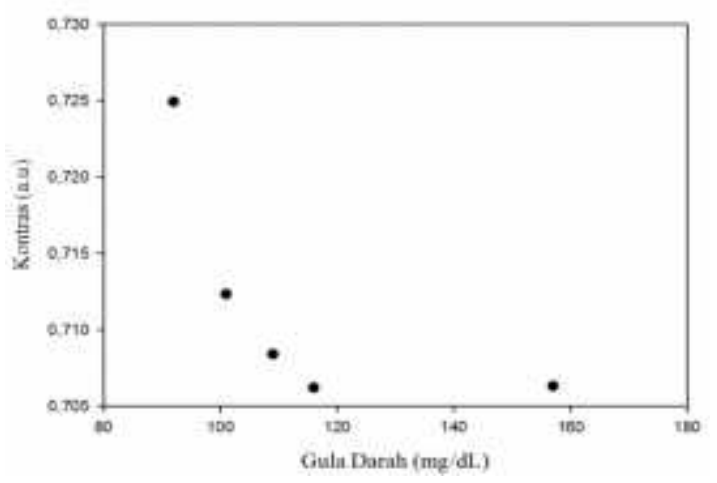

Gambar 5.Grafik Hubungan Kontras Terhadap Kadar Gula Darah

Gambar 5 merupakan grafik hubungan kontras spekel terhadap kadar gula darah selama pengambilan data pada hari ke 8 hingga hari ke 12 dengan konsentrasi 35\%. Nilai kontras spekel menurun ketika kadar gula darah yang diukur menggunakan alat GCU semakin naik. Meningkatnya kadar gula darah setelah diinduksikan aloksan dapat disebabkan oleh dua proses yaitu terbentuknya radikal bebas dan kerusakan permeabilitas membran sel sehingga terjadi kerusakan sel beta pankreas yang berfungsi menghasilkan insulin[12]. 


\section{Visualisasi Detak Jantung Tikus Putih}

Detak jantung dideteksi menggunakan pulse sensor yang terintegrasi pada Arduino Uno sehingga diperoleh visualisasi detak jantung tikus putih seperti pada gambar 4 .

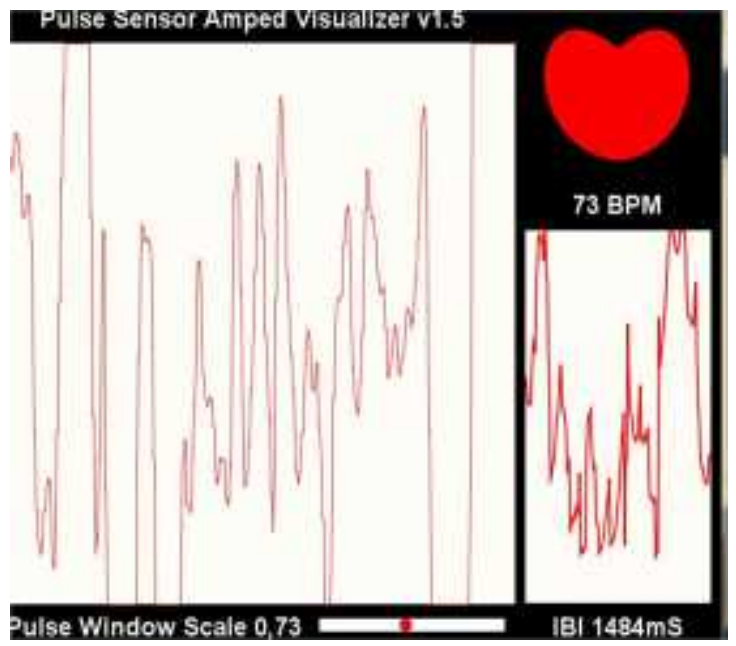

Gambar 6.Visualisasi Detak Jantung Untuk Konsentrasi 35\%

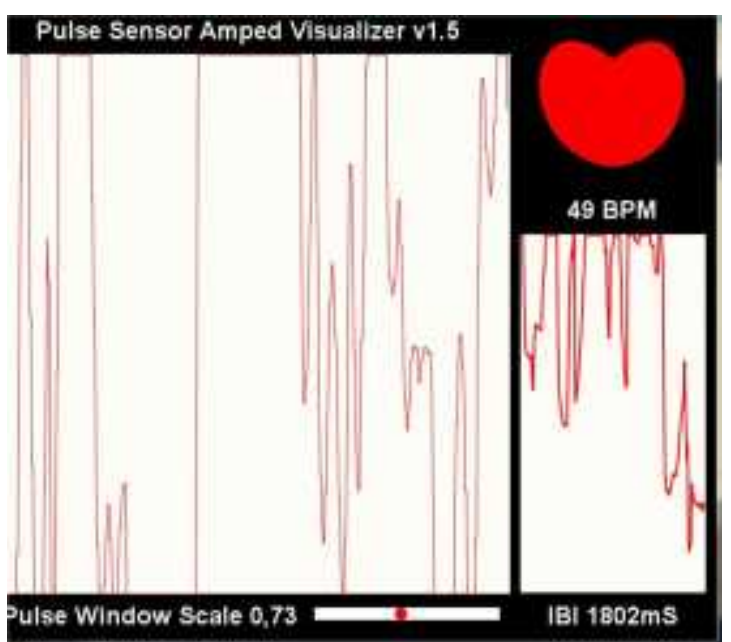

Gambar 7.Visualisasi Detak Jantung Tanpa Konsentrasi Aloksan

Gambar 4 dan 5 merupakan visualisasi detak jantung tikus dengan konsentrasi $35 \%$ dan tanpa aloksan. Faktor yang membuat pulsa detak jantung bervariasi adalah tingginya kadar gula darah yang menyebabkan detak jantung dipacu lebih cepat dibandingkan sampel dengan kadar gula yang rendah. Salah satu komplikasi yang akan dialami bagi penderita diabetes adalah meningkatnya detak jantung. Faktor yang kedua adalah dikarenakan perubahan emosi yang dialami oleh sampel seperti tikus mengalami stress sehingga akan mengakibatkan perubahan pulsa detak jantung[13].

\section{KESIMPULAN}

Berdasarkan hasil penelitian dan analisa visualisasi data mengenai pengukuran kontras dan pulsa detak jantung, maka dapat ditarik beberapa kesimpulan yaitu :

1. Program pengolah citra Diabetic Rats Analyzing Tools berhasil dibangun dengan software scikit image untuk memvisualkan kontras spekel dan histogram sehingga diperoleh nilai kontras.

2. Histogram dari visualisasi jumlah spekel menunjukan bahwa puncak tertinggi disebelah kanan terjadi pada kontras yang tinggi dan puncak yang lebih tinggi disebelah kiri terjadi pada kontras yang rendah.

3. Nilai kontras dipengaruhi oleh kadar gula darah akibat induksi aloksan pada tikus putih. Semakin tinggi kadar gula darah semakin rendah nilai kontras. Nilai kontras tertinggi sebesar 0,72494 a.u pada hari ke 8 dan nilai kontras terendah pada hari ke 10 sebesar 0,70622 a.u.

4. Visualisasi detak jantung tikus putih berhasil ditampilkan pulsa dan nilaibpm tikus putih. Pulsa detak jantung tikus putih dan nilaibeats per minute (bpm) dipengaruhi oleh beberapa faktor seperti meningkatnya kadargula darah dan perubahan emosi. Nilai maksimum detak jantung sebesar $73 \mathrm{bpm}$ pada konsentrasi $35 \%$ dan tanpa aloksan sebesar $49 \mathrm{bpm}$ serta konsentrasi 55\% sebesar 90 bpm.

\section{DAFTAR PUSTAKA}

1. Rendy, M. C. (2012). Asuhan Keperawatan Medikal Bedah dan Penyakit Dalam. Yogyakarta : Nuha Medika. 
2. Timoshina, P. A., Bucharskaya, A. B., Alexandrov, D. A., \& Tuchin, V. V. (2017). Study of Blood Microcirculation of Pancreas in Rats With Alloxan Diabetes by Laser Speckle Contrast Imaging. Biomedical Photonics \& Eng., 3(2).

3. Ragel, S. (2015). Static Laser Speckle Contrast Analysis for Noninvasive Burn Diagnosis Using a Camera Phone-Imager. Journal of Biomedical Optics, 20(8).

4. Briers, D., Duncan, D. D., Hirst, E., Kirkpatrick, S. J., Larsson, M., Steenbergen, W., Stromberg, T., \& Thompson, O. B. (2013). Laser speckle contrast imaging : theoretical and practical limitations. Journal of Biomedical Optics, 18, 066018.

5. Rabal, H. J. \& Braga R. A. (2009). Dynamic Laser Speckle and Applications Optical Science and Engineering, 139. Taylor \& Francis Group. LLC.

6. Zakharov, P., Volker, A. C., Wyss, M. T., Haiss, F., Calcinaghi, N., Zunzunegui, C., Buck, A., Scheffold, F., \& Weber, B. (2009). Dynamic Laser Speckle Imaging of Cerebral Blood Flow. Optics Express., 17(16).

7. Zulkarnain, S. \& Minarni. (2018). Investigasi Penggunaan Metode Laser Speckle Imaging (LSI) Untuk Pengukuran Kadar Gula Darah. Jurnal Fisika UNNES., 8(2), 60-67.
8. Kaspers, A. (2011). Blob Detection Biomedical Image Sciences. Image Sciences Institute. UMC Utrecht.

9. Wang, L., Liufu, C., Yanxue, W., Anand, V., Shuohua, C., Caifeng, Z., Ying, Z., Dongqing, L., Frank, B., Shouling, W., \& Xiang, G. (2015). Resting heart rate and the risk of developing impaired fasting glucose and diabetes : the Kailuan prospective study. International Journal of Epidemiology., 44(2).

10. Wang, R. (2016). Laplacian of Gaussian(LoG).http://fourier.eng.hmc.edu /e161/lectures/gradient/node9.html. Diakses pada tanggal 13 Maret 2018.

11. Mirdyanto, B. \& Hikmah, I. (2015). Pengukuran Standard Deviasi dan Analisis Pengaruh Polarisasi dengan Citra Speckle. Laporan Resmi Laboratorium Optik. Institut Teknologi Sepuluh Nopember.

12. Yuriska, A. F. (2009). Efek Aloksan Terhadap Kadar Glukosa Darah Tikus Wistar. Artikel Ilmiah. Fakultas Kedokteran. Iniversitas Diponegoro.

13. Departemen Kesehatan RI. (2005). Pharmaceutical Care Untuk Penyakit Diabetes Mellitus. Bina Kefarmasian dan Alat Kesehatan. 